\title{
Identification of Retained Austenite by Optical Microscopy and Its Correlation with Mechanical Properties in API-5L-X80 Steel Applied in Pipelines Industry.
}

\author{
M.S. Pereira, ${ }^{*}$ E.M.Orue, ${ }^{*}$ T.M. Hashimoto* \\ * Department of Materials and Technology, Guaratinguetá Campus, \\ São Paulo State University - UNESP, São Paulo, Brasil, 12500-000
}

Recently the pipeline industry has increased the used of steels with high strength-toughness relationship as well as good weldability properties. In order to reach these requirements steels with multiphase microstructure (ferrite, bainite, retained austenite and martensite) have been developed using the concept of Transformation Induced Plasticity (TRIP). Improvements through the TRIP effect are obtained by the retained austenite (RA) transformation in martensite induced by levels of stress and strain. However, the RA identification by optical microscopy [1,2], and even through Xray diffraction techniques, is quite hard specially when it is present in small volume fractions $(<5 \%)$.

Developing a metallographic procedure in order to identify and quantify the RA by optical microscopy has been the main goal of this research, followed by the establishment of a relationship between the RA content and the mechanical properties of the steel after heat treatment which are applied to pipelines production. Several volume fractions of RA have been obtained by different isothermal transformation times for 0,5 to 10 minutes, at $400^{\circ} \mathrm{C}$, in a API-5L-X80 microalloyed steel with $0,05 \% \mathrm{C}$ and $0,0021 \% \mathrm{~B}$. The specimens were prepared by wet grinding (400-2000grit) and polishing (diamond paste 6-0,25 micron). 5\% Nital and $10 \%$ sodium metabisulfite in distilled water have been used to reveal the microstructure. Tensile tests were performed in all conditions of heat treatment in order to determine ultimate tensile strength (UTS), yield strength (YS) and elongation of the steel.

The results showed that the retained austenite identification by optical microscopy is possible after having a sodium metabisulfite etching, showing the RA in white color and darking the other phases. The ferritic phase appears in gray while bainite and martensite appears black (figure 1). Three types of RA localizations in the microstructure have been identified: (A) isolated inside the ferritic grain, (B) isolated inside the bainite and martensite, and (C) in the ferrite, martensite or bainite boundaries (figure 2). Finally it is possible to assume that the maximum RA content was obtained for isothermal transformation times between 3 and 10 minutes. The RA content can be correlated with the best strength-ductility relationship obtained by tensile tests (table 1) showing good perspectives for applications in pipelines manufacturing.

\section{References}

[1] Y. Sakuma et al., Metallurgical Transaction A, vol.23 (1992) p.1221-32.

[2] W.C. Jeong et al., Mater. Sci. Eng., 165 (1993) p.1-8. 


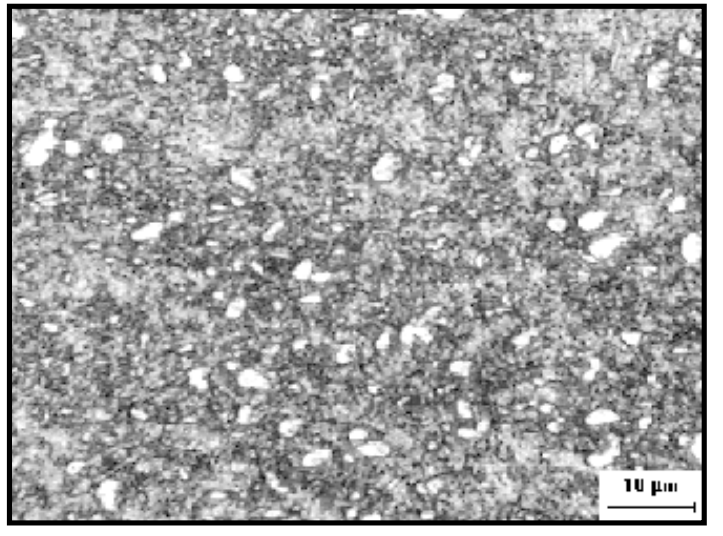

(a)

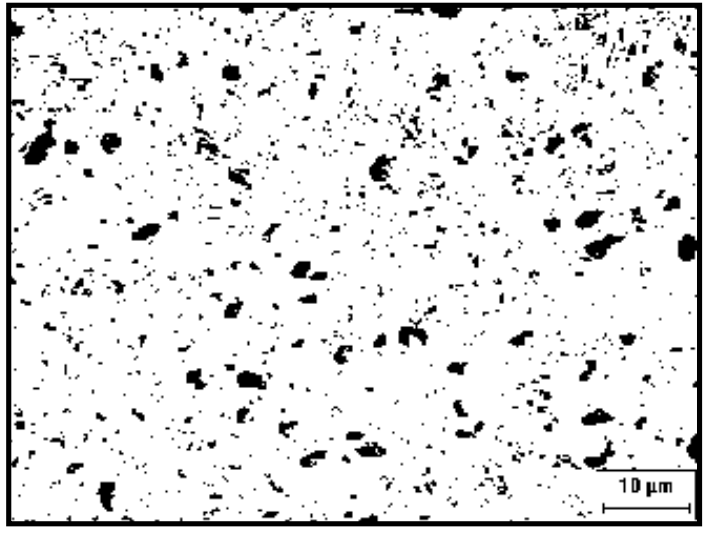

(b)

Figure 1. (a) Microstructure of API-5L-X80 microalloyed steel showing retained austenite (white), bainite plus martensite (black) and ferrite (gray). (b) the same photomicrography with image digital treatment to emphasize retained austenite (black).

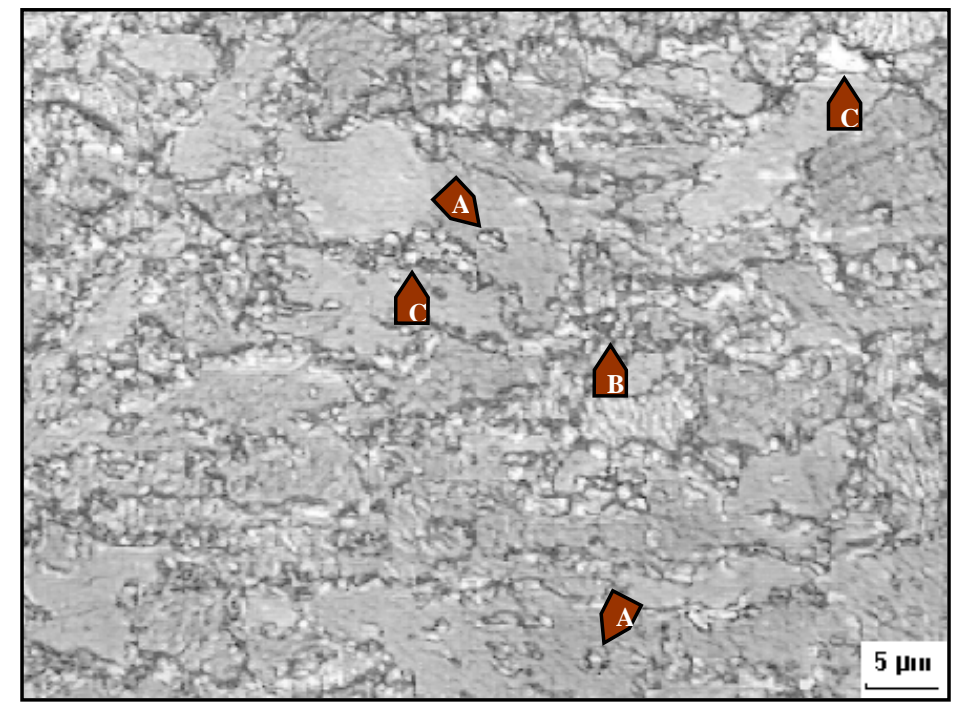

Figure 2. Microstructure of API-5L-X80 microalloyed steel showing three types of RA localizations: (A) isolated inside the ferritic grain, (B) isolated inside the bainite and martensite, and (C) in the ferrite, martensite or bainite boundaries.

Table 1. Mechanical Properties of API-5L-X80 microalloyed steel.

\begin{tabular}{|c|c|c|c|}
\hline $\begin{array}{c}\text { Isothermal Holding } \\
\text { Time (minutes) }\end{array}$ & $\begin{array}{c}\text { Ultimate Tensile } \\
\text { Strength }(\mathrm{MPa})\end{array}$ & $\begin{array}{c}\text { Yield Strength } \\
(\mathrm{MPa})\end{array}$ & $\begin{array}{c}\text { Elongation } \\
(\%)\end{array}$ \\
\hline 0,5 & 769 & 451 & 18,75 \\
\hline 3 & 696 & 434 & 21,26 \\
\hline 10 & 672 & 476 & 21,11 \\
\hline 30 & 682 & 501 & 20,75 \\
\hline
\end{tabular}

